\title{
Overcoming cross-cultural group work tensions: mixed student perspectives on the role of social relationships
}

\author{
Jenna Mittelmeier ${ }^{1} \cdot$ Bart Rienties $^{1} \cdot$ Dirk Tempelaar $^{2}$ • \\ Denise Whitelock ${ }^{1}$
}

Published online: 23 February 2017

(C) The Author(s) 2017. This article is published with open access at Springerlink.com

\begin{abstract}
As universities worldwide rapidly internationalise, higher education classrooms have become unique spaces for collaboration between students from different countries. One common way to encourage collaboration between diverse peers is through group work. However, previous research has highlighted that cross-cultural group work can be challenging and has hinted at potential social tensions. To understand this notion better, we have used robust quantitative tools in this study to select 20 participants from a larger classroom of 860 students to take part in an in-depth qualitative interview about cross-cultural group work experiences. Participant views on social tensions in cross-cultural group work were elicited using a unique mediating artefact method to encourage reflection and in-depth discussion. In our analysis of emergent interview themes, we compared student perspectives on the role of social relationships in group work by their academic performance level. Our findings indicated that all students interviewed desired the opportunity to form social relationships with their group work members, but their motivations for doing so varied widely by academic performance level.
\end{abstract}

Keywords Group work · Collaborative work · Social connections · Social integration · International students

\section{Introduction}

With more than 4.5 million international students registered at universities worldwide (OECD 2014), higher education campuses have become unique spaces for social interaction between

Jenna Mittelmeier

jenna.mittelmeier@open.ac.uk

1 Institute of Educational Technology, The Open University, Walton Hall, Milton Keynes MK7 6AA, UK

2 School of Business and Economics, Maastricht University, Tongersestraat 53, 6211 LM Maastricht, Netherlands 
peers from different countries. One prominent source of interaction between domestic and international students is collaborative group work, which has previously been shown to enhance the student learning experience (Bliss and Lawrence 2009; Chang 2006; Denson and Zhang 2010; Kember 2008; Lavy 2016) and provide students opportunities to encounter new ideas and values (Levin 2005).

At the same time, it has been acknowledged that simply placing students into groups with peers from other countries does not immediately lead to productive collaboration (Moore and Hampton 2015; Van den Bossche et al. 2006). Initially, there are often social tensions between diverse group members (Takahashi and Saito 2013), perhaps due to a lack of shared understanding about one another's backgrounds and experiences (Fozdar and Volet 2012; Harrison and Peacock 2009; Moore and Hampton 2015). Indeed, previous research has hinted that developing social relationships between diverse group members may be key to encouraging collaboration (Curşeu et al. 2011; Mathieu et al. 2000). At the same time, it has been highlighted that students with high academic performance (i.e. grades), tend to form larger, more diverse social learning networks (Gasevic et al. 2013; Hommes et al. 2012), thus suggesting that social experiences in group work may vary between students of differing performance levels.

However, limited research has specifically focused on the role of social relationships in encouraging collaboration. Thus, one goal of this study is to highlight student voices on the subject of social tensions in group work with peers from different countries. A second goal is to better understand the nuances in social experiences between students of varying academic performance levels. Finally, as little is known about the role of the teacher in developing these relationships, we aim to highlight student expectations of teachers in developing social capital between diverse group work participants. Using in-depth qualitative methods coupled with robust quantitative tools in a highly diverse multidisciplinary business module with 860 students, in this article, we analyse 20 interviews to compare cross-cultural group work experiences and expectations between students of varying academic performance levels.

\section{Cross-cultural group work}

Cross-cultural group work (i.e. collaborative learning activities between domestic and international students) provides a number of benefits to students, such as the development of key graduate employability skills (Denson and Zhang 2010; Kember 2008; Spencer-Oatey \& Dauber, 2017). Group work can also benefit international students' academic and social adjustments (Wang 2012). Similarly, it has been highlighted that working in small groups with students from different countries over a sustained period of time can lead to more diversified social networks within large classrooms (Rienties et al. 2013, 2014).

However, other research has demonstrated that cross-cultural group work is often fraught with tension. For example, Fozdar and Volet (2012) demonstrated that, although students felt positive about working with peers from other countries, they found the work challenging. In the UK, Harrison and Peacock (2009) found that many domestic students felt negative about working with international students. Similarly, Moore and Hampton (2015) highlighted that many students (particularly domestic students) preferred to work with those from their own background. In a problem-based learning environment, Singaram et al. (2011) demonstrated self-segregation by cultural background between students in collaborative tutorials.

Thus, current research has demonstrated that simply assigning students to groups with peers from other countries is not automatically beneficial. For example, Decuyper et al. (2010) have 
highlighted that successful group work requires a 'dialogical space' (i.e. cooperation through constructive conflict), which is established by building trust between group members. Van den Bossche et al. (2006, p. 514) have argued that group work is about more than merely 'putting people together,' and that more attention is needed on the social conditions that underpin collaboration. It is this notion - the role of social relationships - that will be discussed next.

\section{Social relationships and group work}

Building diverse, supportive social relationships (i.e. established personal and working connections and friendships) has been found to positively impact the overall student transition experience (Maunder et al. 2013). For example, Wilcox et al. (2005) found social relationships and friendships to be important influences on first-year attainment and progression. Similarly, Hommes et al. (2012) highlighted social relationships with peers as a powerful predictor for learning.

Yet, forming relationships with peers from other countries can be challenging, particularly for international students. Indeed, studies have demonstrated that many international students have limited friendships with host students (Gareis 2012; Schartner 2015). Similarly, Harrison and Peacock (2009) suggested that host students often demonstrated 'passive xenophobia' towards international students. Sherry et al. (2010) additionally demonstrated in an analysis of 121 surveyed international students in Spain that many encounter a lack of understanding about their backgrounds from domestic peers. These issues add complexities to unpacking the role of social relationships during collaboration in diverse classrooms.

In a collaborative group work context, research has similarly demonstrated that social relationships may play an important role. For example, 'social presence' is one of three major foundations of collaborative learning experiences highlighted by Community of Inquiry literature (along with teaching and cognitive elements) (Akyol and Garrison 2013; Garrison et al. 1999). In teamwork literature, the importance of shared mental models has been previously highlighted (i.e. the ability to understand the strengths and weaknesses of one's group members and form a 'common ground' for collaboration) (Decuyper et al. 2010; Mathieu et al. 2000). Similarly, Curşeu et al. (2011) demonstrated that social relationships among peers in small groups reduced conflicts, thus leading to more cognitive gains.

At the same time, research has hinted at social tensions between students in group work. Rienties et al. (2013) found that many students in a large multidisciplinary classroom formed social relationships with those from the same country or academic discipline, rather than with their assigned group members. While observing small groups in problem-based learning environments, Takahashi and Saito (2013, p. 702) found students were initially 'tense and quiet,' but became more active within their groups after getting to know one another.

Limited research has suggested that teacher or institutional intervention may help alleviate such tensions. For example, in an analysis of 27 student interviews by Kimmel and Volet (2012), one suggestion was that 'cohort-like' classrooms may encourage group work satisfaction. Davies (2009, p. 574) has also suggested that teachers should give students ample time for 'socialising and a sense of group solidarity.' Yet, Moore and Hampton (2015) found that many students perceived little to no intervention from their teacher in improving group work conditions. Therefore, more research is needed to further unpack teacher roles in dissipating social tensions in group work. One additional consideration is whether students from differing academic performance levels need different types of social supports as their experiences on campus may vary, which will be discussed next. 


\section{Academic performance and social relationships}

Previous research has demonstrated that high-performing university students tend to demonstrate stronger social relationship networks on campus. For example, studies have found that high-performing students tend to be more central (i.e. connected) within the classroom social network (Gasevic et al. 2013; Hommes et al. 2012). Similarly, Mittelmeier et al. (2016) found that higher performing students had more diverse social and learning relationships with peers, which led to higher participation in group work activities. Rienties et al. (2015) also highlighted that academic leaders are more likely to act as social 'bridge-builders' between students with diverse backgrounds. These studies demonstrate that it is worth unpacking whether students from different performance levels reflect on social tensions in group work and teacher roles in facilitating social relationships differently.

\section{Research questions}

Current research has found that social relationships play an important role in students' educational experiences and that higher performing students tend to possess more social capital. Similarly, social tensions have been highlighted as a barrier to positive group work perceptions and experiences. However, limited research has considered, particularly from a student perspective, why and how social relationships impact group work perceptions and what role they play in encouraging (or discouraging) collaboration. Similarly, few studies have considered whether students of varying academic performance levels perceive the role of social relationships in group work differently. To address these gaps, we consider the following questions in this study:

1. What role do students believe social relationships play in the success of cross-cultural group work tasks?

2. How does academic performance influence student views on social relationships in crosscultural group work?

We additionally recognise a pressing need for research on this topic to link explicitly to practice, as limited research has considered student expectations of teachers in developing social relationships between cross-cultural group work members. Thus, we also consider the following:

3. How do students perceive the role of the teacher in overcoming tensions between diverse group members in cross-cultural group work?

\section{Methodology}

\section{Setting and participants}

This study was undertaken with first-year undergraduate students studying a multidisciplinary statistics module in a business school at a distinguished university in the Netherlands. This business school has adopted a problem-based learning curriculum and students have frequent opportunities to work in small groups both inside and outside the classroom (Gijselaers 1995; 
Van den Bossche et al. 2006). Students at this university study in a truly diverse and international environment. Indeed, the university was listed as one of the top 20 'most international' universities in the world by Times Higher Education, with $49 \%$ of students and $40 \%$ of staff originating from abroad. Over 100 countries are represented on campus, with large cohorts from Germany and Belgium.

Interview participants were selected from a large-scale classroom of 1318 students. Within this classroom, 269 students were repeating the course. Recent research has highlighted that campus experiences vary widely by year of study (Zaitseva et al. 2013) and that social relationships are particularly influential on first-year satisfaction (Wilcox et al. 2005). Thus, we sought to explore the experiences of students at the same stage of social integration in this study by only comparing experiences of first-year students. Repeating students in this course were in their second year of study and were excluded from our analysis as they might have advanced more in their social integration process. Information about students' grades was also missing from a further 189 students taking the module for the first time, and they were likewise not included in the analysis. Missing data could be due to a number of reasons, as students may have postponed or suspended their studies, or simply missed exams due to personal circumstances. Thus, a total of 860 students were included in the analysis for this study. High cultural diversity was demonstrated between these 860 students, with $79.3 \%(n=682)$ of students originating from outside the Netherlands, representing 36 countries. A large group of international students were of German origin $(48.7 \%, n=419)$. In terms of gender, $54.5 \%(n=469)$ of students in the classroom were male.

Altogether, 20 students (see next section) from the larger classroom participated in an indepth and semi-structured interview. Interview participants were relatively diverse, with $10 \%$ $(n=2)$ from the Netherlands (host national students), 15\% $(n=3)$ from Germany, $40 \%$ from other European countries (non-Dutch and non-German) $(n=8)$ and 35\% from non-European countries $(n=7)$. Slightly more males $(60 \%, n=12)$ participated than females, which is representative of the larger sample.

\section{Procedure}

Invited participants were selected after an initial analysis of the larger quantitative data set, as demonstrated in previous studies (Rienties et al. 2015). To ensure that a representative sample was selected for the interviews, k-means cluster analysis was applied. As we were interested in the role of academic performance on student perceptions of social tensions in group work, we applied the cluster analysis to the larger sample to divide all 860 students into three clusters based on their grades. Participants in this business school took four courses during their first term, three of which were multidisciplinary: quantitative methods (QM) (the course this article describes), marketing and management (MoM), and accounting (ACC). As students in all disciplines were required to take these three multidisciplinary courses, we used the three final grades from the modules in the cluster analysis. Participants were graded on a 0-10 scale in each module, with 10 indicating a perfect score.

The cluster analysis divided the 860 students into three clusters, as highlighted in Table 1. Cluster $1(n=240,30 \%)$ included high academic performers. Cluster $2(n=339,39 \%)$ contained mid performers, while low performers were included in cluster $3(n=281,31 \%)$. At this particular university, a grade of 5.5 is required to pass, meaning most students in cluster 3 will not successfully finish their first year. 
Table 1 Average grades by cluster

\begin{tabular}{lllll}
\hline Cluster & \# of students & Avg QM grade & Avg MoM grade & Avg ACC grade \\
\hline Cluster 1: high performers & 281 & 9.3 & 7.8 & 7.7 \\
Cluster 2: mid performers & 339 & 6.9 & 6.3 & 5.8 \\
Cluster 3: low performers & 240 & 3.8 & 5.1 & 4.2 \\
\hline
\end{tabular}

In order to also ensure diversity in our sample, we next assigned each student to one of four categories by nation of origin: Dutch, German, 'other' European (i.e. non-Dutch or German) and non-European. The Dutch category was selected as the host university was located in the Netherlands. German students were given their own category, as they are a strikingly large group of international students at this university (outnumbering the local population), and their cohort identity may differentiate their experience. Finally, we opted to categorise the remaining international students into two categories: (1) 'other' European (defined by European Union membership) and (2) non-European. This decision was made to explore the complexities of integration experiences for those students designated in an immigrant category (i.e. requiring a visa for legal residence in Europe).

A sample quota based on cluster and nation of origin category was then used to invite selected participants to be interviewed. Altogether 84 students were invited for an interview and 20 participated, which is a response rate of $23.8 \%$. Potential interview participants were invited via their university email address to take part in this study. Participation was not compulsory, but participants did receive a gift voucher worth 15 Euro in return for their time. Of the 20 participants, 5 were in cluster 1 (25\%), 8 were in cluster $2(40 \%)$ and 7 were in cluster $3(35 \%)$, indicating a fairly good representative sample of the wider classroom.

The interviews took place in a private conference room on campus and lasted approximately 45 minute. The format was semi-structured, and interview questions were drafted based on a review of current literature in consideration with our research questions (Lichtman 2013). A baseline set of questions was asked of all participants, and questions were adapted or added in response to the dialogue as needed. The interviews were conducted in English, which is the primary language used for teaching and academic activities at this particular university. Participants were assured of the confidentiality of all statements during the interviews, and the interviews were conducted by a member of the research team who was not affiliated with the university, so as to avoid any conflicts of interest.

Participants were first asked a series of 'warm-up questions,' in order to build rapport and establish trust (e.g. Can you tell me about your experiences so far working in small groups? Have you had the opportunity to work with classmates from other countries?). As culture is a particularly personal and sensitive topic, a visual mediating artefact was then introduced to encourage in-depth discussion and reflection. This method has been highlighted in previous research (Bahn and Barratt-Pugh 2013) as a powerful way to elicit complex thoughts and feelings in an environment that is perceived as 'safe' by the participant. The visualisation provided to participants (shown in Fig. 1) depicted an example of a cross-cultural group work project, including information about the participants, such as region of origin, number of contributions made and categories of contributions (i.e. social, teaching or academic content contributions). All information provided in the visualisation was adapted from an authentic group work activity compiled in previous research by members of the research team (Mittelmeier et al. 2016) The group work activity depicted in the visualisation was relevant 


\section{Case Study}

Student 2, from East Asia: Speaks 2 times

0 times to organise the group/activity 2 times to contribute academic content 0 times socially

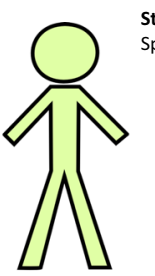

Student 1, domestic student from the Netherlands: Speaks 23 times

4 times to organise the group/activity

7 times to contribute academic content

12 times socially

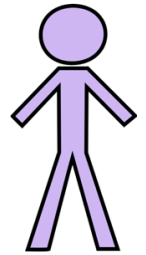

Student 3, from Latin America:

Speaks 6 times

1 time to organise the group/activity

2 times to contribute academic content

3 times socially

Student 5, from East Asia:

Speaks 7 times

1 times to organise the group/activity

5 times to contribute academic content

1 times socially
3 times to organise the group/activity

6 times to contribute academic content

4 times socially
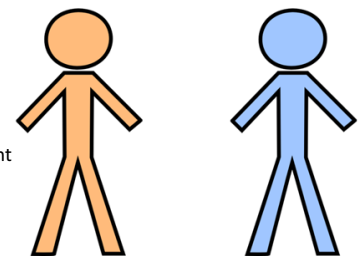

Fig. 1 Visualisation provided to participants during interviews as mediating artefact

to participants' own course experiences, as it was conducted using a problem-based learning activity similar in nature to the curriculum design of their degree programme.

After reviewing the visualisation, participants were then asked a series of in-depth questions about it (e.g. What do you feel is going well in this group? What frustrations might students in this group be feeling? Why do you feel some students participated more than others?). Throughout the discussion, the interviewer connected statements made by the participant to their own personal experiences when possible (e.g. Can you tell me about a time that you experienced this when participating in group work? How does this reflect what you have seen in your courses?). Finally, participants were asked about potential interventions or resources that they felt would help encourage more equal participation (such as: What would you suggest these students do to help the group work activity go more smoothly? What resources or interventions should the teacher provide to help this group?). When applicable, this portion of the interview was discussed against the backdrop of participants' own expressed experiences.

The study procedure and all documents used (interview questions, visualisation, etc.) were approved by the institution's ethical review board, in accordance with the British Education Research Association (BERA)'s ethical guidelines. In this article, we have included demographic information about participants, such as gender and country of origin. In a few cases, participants were the sole representative from their home country in the course. In order to protect the identities of these students, we have chosen to provide a region of origin, rather than an exact country, in connection to participant quotes in the 'Results' section.

\section{Data analysis}

Interviews were transcribed and analysed using thematic analysis, as recommended by Lichtman (2013). Thematic codes consisted of pre-existing themes from the interview questions, as well as emerging themes from a preliminary analysis of the interview transcripts. Altogether, our thematic analysis identified 22 themes. Influenced by recent research (Akyol 
and Garrison 2013; Garrison et al. 1999), codes were arranged into three categories: social elements (i.e. those related to social relationships and culture) ( 9 themes), teaching elements (i.e. those related to the teacher, scaffolding and instruction) (7 themes), and cognitive elements (i.e. those related to the task itself) (6 themes). The unit of analysis in our coding system was one paragraph (i.e. one full response to an interview question), and paragraphs could be given multiple codes. In this article, we specifically focus on the social aspects in our coding system, which best answer our research questions. Definitions of codes in the social category are given in Table 2.

Steps were taken to ensure the reliability of our coding system, which occurred in two stages. First, after an initial development of the thematic codes, two additional members of the research team individually coded a selection of interviews. Cohen's kappa was used to analyse inter-rater reliability, which indicated moderate to good agreement $(\kappa=.710)$. Afterwards, notes were compared between researchers and revisions to the coding system were made to counter any disagreements. In the second stage, an independent reviewer analysed an additional section of the interviews using the revised coding system. Cohen's kappa was again used to demonstrate inter-rater reliability, which indicated good agreement $(\kappa=.834)$.

\section{Results}

Overall, a total of 1582 codes were recorded, of which $39.1 \%(n=618)$ were in the social element category. Participants in cluster 1 contributed an individual average of 94.4 $(\mathrm{SD}=29.28)$ total codes and 31.2 social element codes $(\mathrm{SD}=7.76)$. Cluster 2 participants contributed an individual average of $71.6(\mathrm{SD}=17.75)$ codes and $27.75(\mathrm{SD}=12.14)$ social element codes. Finally, participants in cluster 3 contributed an individual average of 76.7 codes $(\mathrm{SD}=17.66)$ and 24.28 social element codes $(\mathrm{SD}=11.40)$. A descriptive summary of social element themes by cluster is depicted in Table 3 . We considered whether there were differences between clusters in terms of the quantity of statements for each code and found only a few differences. First, high-performing students on average discussed cultural influences with working with diverse group members more often. Second, low-performing students more frequently discussed the role of forming social relationships with group members.

Table 2 Summary and definition of social codes

\begin{tabular}{|c|c|}
\hline Code & Definition of code \\
\hline Cultural influences & $\begin{array}{l}\text { Statements related to how cultural traits influence behaviours in group work, } \\
\text { including statements about cultural distances and cultural differences }\end{array}$ \\
\hline Social relationships & $\begin{array}{l}\text { Statements about the impact of social relationships and building connections between } \\
\text { group members }\end{array}$ \\
\hline Language & Statements about language barriers, skills and use \\
\hline Openness & $\begin{array}{l}\text { Statements related to group members' 'openness' towards one another (or lack } \\
\text { thereof), including comments related to cultural sensitivity, respect and } \\
\text { willingness to communicate }\end{array}$ \\
\hline Emotional reactions & Statements related to participants' emotional reactions to participating in group work \\
\hline Social contributions & Statements related to speaking socially during a group work activity \\
\hline $\begin{array}{l}\text { Previous international } \\
\text { experiences }\end{array}$ & $\begin{array}{l}\text { Statements about how previous international experiences and experiences with } \\
\text { diversity impact how one contributes to cross-cultural group work }\end{array}$ \\
\hline Interactions & $\begin{array}{l}\text { General statements about interactions between participants, including examples of } \\
\text { positive and negative interactions }\end{array}$ \\
\hline Communication & $\begin{array}{l}\text { Statements about communication issues and factors that relate to good } \\
\text { communication between group members }\end{array}$ \\
\hline
\end{tabular}


Table 3 Number of codes by category and cluster

\begin{tabular}{|c|c|c|c|c|c|c|c|c|c|}
\hline \multirow[t]{2}{*}{ Code } & \multirow[t]{2}{*}{$\begin{array}{l}\text { Total } \\
N\end{array}$} & \multirow{2}{*}{$\begin{array}{l}\% \text { of } \\
\text { total } \\
\text { codes }\end{array}$} & \multirow{2}{*}{$\begin{array}{l}\text { \# of } \\
\text { participants } \\
\text { coded }\end{array}$} & \multicolumn{2}{|c|}{$\begin{array}{l}\text { Cluster } 1 \text { high } \\
(n=5)\end{array}$} & \multicolumn{2}{|c|}{$\begin{array}{l}\text { Cluster } 2 \text { mid } \\
(n=8)\end{array}$} & \multicolumn{2}{|c|}{$\begin{array}{l}\text { Cluster } 3 \text { low } \\
(n=7)\end{array}$} \\
\hline & & & & $\begin{array}{l}\text { Average } \\
\text { individual }\end{array}$ & $\mathrm{SD}$ & $\begin{array}{l}\text { Average } \\
\text { individual }\end{array}$ & $\mathrm{SD}$ & $\begin{array}{l}\text { Average } \\
\text { individual }\end{array}$ & $\mathrm{SD}$ \\
\hline Cultural influences & 152 & 9.8 & 20 & 11.20 & 5.35 & 6.50 & 3.66 & 6.29 & 2.75 \\
\hline Social relationships & 148 & 9.5 & 20 & 6.00 & 2.91 & 4.63 & 3.81 & 11.57 & 4.99 \\
\hline Language & 102 & 6.5 & 20 & 4.80 & 1.48 & 4.75 & 1.98 & 5.71 & 2.92 \\
\hline Openness & 64 & 4.1 & 18 & 2.40 & 3.21 & 3.50 & 2.82 & 3.42 & 1.71 \\
\hline Emotional reactions & 51 & 3.3 & 15 & 1.60 & 1.82 & 3.50 & 3.46 & 2.14 & 1.22 \\
\hline Social contributions & 40 & 2.9 & 15 & 2.40 & 2.30 & 2.00 & 1.69 & 1.71 & 1.79 \\
\hline $\begin{array}{l}\text { Previous } \\
\text { international } \\
\text { experiences }\end{array}$ & 24 & 1.5 & 12 & 1.00 & 1.00 & 1.00 & 1.00 & 1.57 & 1.40 \\
\hline Interactions & 21 & 1.4 & 14 & 1.20 & 0.84 & 1.00 & 1.07 & 1.00 & 0.82 \\
\hline Communication & 16 & 1.0 & 10 & 0.60 & 0.55 & 0.88 & 1.12 & 0.86 & 1.22 \\
\hline
\end{tabular}

Although students may have discussed the same general topics in terms of quantity, we were particularly interested in understanding qualitative similarities and differences in student opinions, especially between those of varying performance levels (research question 2). Thus, comparisons of coded statements were made by cluster (i.e. performance level), which will be discussed next.

\section{Common themes in all clusters}

Several themes were common to participants in all clusters and are important to note. Perhaps most prevalent was the notion that all participants wished to have the opportunity to build social relationships with their fellow group members. This is interesting, as there were no interview questions that specifically addressed social relationships between group members, yet this was a prominent emerging theme of discussion that was voluntarily offered by all 20 interview participants. There was also an overall perception among all participants that the 'vibe' within the classroom and between group members is an important element of group work. Participants highlighted that building an open and inclusive environment through social relationships is key to successful collaborative work.

I think the most important thing is being open to each other. If you're in a group and you're afraid to say something, then you're going to miss out on a lot, because every input is valuable because you can grow from it. (Participant 1, male, Eastern European, $\mathrm{GPA}=6.67$, cluster 2 )

That you don't feel like you're lost or you don't belong in that group, that's really important. So you feel included, that's really important. That you can talk to each other, like in a familiar way and that you harmonise. I think that's really important. That's the main thing or main goal of an intercultural group you're supposed to work on. (Participant 16, male, German, GPA $=4.83$, cluster 3)

Yet, the reasons for why participants wanted to build social relationships with peers varied between those in different clusters, which will be highlighted in the following sections. 
An additional common theme among all 20 participants was the importance of the use of the lingua franca (in this case, English) in encouraging collaboration and communication in group work.

It's [people speaking their native language during group work] very, very frustrating. I think it really de-motivates the class because if you're trying to speak and you're trying to say something and everyone is having these little conversations that you don't even understand, it de-motivates the group and they can't focus. It just means that everyone can't communicate. (Participant 11, female, Dutch, GPA = 4.33, cluster 3)

Alright we say lingua franca, but for example somebody, a German guy who does not work on English, he asks in German and that makes the first step into speaking German. Then it starts slowly, slowly, slowly speaking more and more German. So I really think the communication plays a very important role in the group bonding. (Participant 15, male, Greek, GPA $=5.67$, cluster 2)

Similarly, many participants (16 of the 20) highlighted that the teacher or tutor plays an essential role in encouraging the use of a common language between group members in the classroom. In this regard, participants particularly wanted teachers to assign them to highly diverse groups with peers from other countries.

I think the mix of countries is better because it will improve your communication skills. I think people always get used to speaking their mother tongue. Like if I have a Chinese student that is with me, sometimes I will forget the lingua franca, to speak English. So sometimes I will turn to speak Chinese with my Chinese mates. (Participant 17, female, Chinese, GPA $=7.33$, cluster 1 )

They should try to make, especially with tutors, the groups as international as possible, because if they put only domestic students in one group, it becomes really easy for them to work. They should challenge them to the max so that they cannot speak their mother language and can cooperate with others on other activities. (Participant 6, female, Eastern European, GPA $=4.83$, cluster 3)

In addition to language, nearly all participants (19 of the 20) noted that the opportunity to work with diverse peers was a positive challenge that could help them gain essential skills.

I feel you need to know we live in a convoluted world with all sorts of nationalities, and the world is getting more international every day. I feel like you need that to be part of the real world. (Participant 18, male, Latin American, GPA = 5.00, cluster 2)

Yet, despite these commonalities, there were several key differences between participants in different clusters, which will be discussed in the following sections.

\section{Cluster 1: high-performing students}

The five participants in cluster 1 tended to think of themselves as leaders and all viewed crosscultural group work as an opportunity to gain skills for future employment. Yet, when highperforming students talked about forming social relationships with diverse group members, they did not typically refer to educational benefits of getting to know their group members. Instead, four of the five highlighted that forming social bonds can make group work more fun or entertaining and less 'boring'. For example: 
For me, I think some social talk is much easier than the academic topics, and people are more willing to speak about their daily life, for instance their hobbies, than speaking about the [group work] topic. It's boring. (Participant 17, female, GPA = 7.33, Chinese)

It's boring to be with always the same people because you have nothing to tell them if they are from the same places and the same country. (Participant 20, male, GPA $=8.67$, Belgian)

When discussing the role of the teacher or university in building social relationships within the classroom, those in cluster 1 all referred to the benefits for other, less active students rather than themselves. For instance:

Sometimes they [less active students] need to be pushed into this, pushed into the cold water of saying something and trying it out ... I think it is a necessary experience and if you push such students here at [university name] to be socially active, especially those from other regions or continents, this is something which is only going to help them in the long run. (Participant 9, male, GPA $=9.67$, American)

I think it's just with these people [international students] that they need two months to get acquainted to you and then in the end, they will probably be more likely to share their ideas or to give more input. (Participant 14, male, GPA $=8.67$, Dutch)

At the same time, participants in cluster 1 all felt that interventions, such as more in-depth introductions or icebreaker activities, may benefit less active students. However, they tended to feel that these should be the responsibility of the group members (i.e. students), rather than teachers.

I think introduction is not enough, but for tutor... I don't know, I think it depends on the students themselves. I don't think the tutor can do much to help this. (Participant 17, female, GPA = 7.33, Chinese)

Instead, those in cluster 1 all viewed the teacher's role as that of developing students' 'soft skills,' such as communication and collaboration skills. Yet, these were often viewed as separate from building social relationships.

Especially for business, the university has to prepare not just the academic part and business knowledge, because in business you need not just theoretical skills, but also soft and practical skills. The university has to push them [less active group members] into developing their soft skills. (Participant 9, male, GPA = 9.67, American)

Four of the five participants in cluster 1 additionally felt that students at the university were already open to working with those from different countries. There was frequent mention that openness in cross-cultural situations is 'natural'.

So here in [university name] especially, everybody comes from different countries, at least at this uni. That really helps because you just get a larger point of view. You cannot only look at yourself as yourself, but you can look at yourself in the world. I don't know how to explain it, but you feel part of something. You feel like you belong. (Participant 13 , female, GPA $=7.83$, Italian)

Altogether, high-performing students were often highly driven individuals who viewed social relationships in group work as a benefit to their personal enjoyment rather than their 
learning. However, these participants clearly highlighted that social relationships are necessarily for the adjustment of 'other,' lower performing students.

\section{Cluster 2: mid-performing students}

In comparison, the eight participants in cluster 2 discussed more about how social relationships can impact group dynamics and productivity, unlike participants in cluster 1 who frequently viewed social relationships and group dynamics separately. Cluster 2 participants often commented that forming social bonds with their group members would benefit communication and co-creation of knowledge. For example:

Wasn't there a thing in management, like the water fountain thing? That people in the break room, they learn more and get more work done because they got to know each other in the break room and socially than just working. So I mean, if that works in the real life why wouldn't that work in the classroom? (Participant 18, male, GPA $=5.00$, Latin American)

Similarly, all but one in cluster 2 noted the importance of group members being comfortable with one another in order to encourage participation.

I think the most important thing is to make people comfortable, because if you don't feel comfortable, then you won't say anything. (Participant 19, female, GPA =6.17, German)

Participants in cluster 2 were also more likely to discuss negative social experiences in group work. Unlike those in cluster 1, who often felt that cross-cultural communication was relatively natural, there was more of a perception of social tensions for all those in cluster 2 .

When you are not speaking socially, you might feel kind of rejected. I think you're always feeling that awkward moment when you are not speaking with people. I think that maybe the others don't know how to get on with them [those who are quiet], because they are not speaking so they will not be willing to speak to them. It will always be weird. (Participant 2, male, GPA $=6.33$, Swedish)

I know what's going on in Europe and the lifestyle, but I think that people sometimes have a prejudice in their minds because I'm from [outside Europe]. Even a girl asked me, she said 'Maybe you can talk about religion,' and I'm not religious at all so I was just thinking, 'No way!' (Participant 12, female, GPA $=5.67$, Middle Eastern)

The role of the teacher in developing social relationships and collaboration was discussed more frequently with participants in cluster 2 . However, five of the eight participants were unconfident in their teacher's ability to successfully decrease group tensions.

I don't really want to say all the things that everybody used to say, like 'everybody work together,' blah, blah, blah. I mean, so many advice and so many times we have heard everything from high school teachers, from tutors, from professors. But the thing is, it doesn't really make a change in people's minds. (Participant 15, male, GPA = 5.67, Greek)

Two of the remaining three participants felt that teacher interventions, although wellintentioned, might not be received positively by students.

Maybe if they had some kind of social activities before the starting of the group, like team-building and stuff. It kind of makes the people feel more comfortable. But I think it 
won't be accepted so well because we are not in the kindergarten, we are in university.

(Participant 6, female, GPA $=5.00$, Bulgaria)

Altogether, students in cluster 2 felt that social relationships are a necessary component of successful group collaboration and were more likely to demonstrate tensions as a natural component of working with students from other backgrounds.

\section{Cluster 3: low-performing students}

The seven participants in cluster 3 tended to feel less comfortable with group work and often admitted to contributing less than their peers. At the same time, all participants in cluster 3 frequently noted that social relationships are essential and necessary components for productivity in cross-cultural group work, using stronger language than participants in cluster 1 or 2. Six of the seven participants highlighted that knowing their group members on a more personal level helps them feel more comfortable and more likely to participate.

I was in that situation as well when I was in a group and I didn't know anyone and they ... all knew each other and didn't want to do anything with me or something. I didn't feel as part of the group. I think that's the main goal of a group: to get to know each other, to feel comfortable in that group. (Participant 16, male, GPA $=4.83$, German)

This tutorial ... I'm not as close with them and I don't feel as comfortable with them. I'm less likely to put myself out there. I'll restrict myself just a tiny bit because there's something subconsciously holding me back. (Participant 11, female, GPA = 4.33, Dutch)

Although participants in cluster 1 typically felt that collaboration happens naturally, those in cluster 3 all felt that cross-cultural group work is inherently socially awkward. This was typically expressed in more definite terms than participants in cluster 2 .

The first time we met, we didn't know each other, but then we kept working together. I think you should discover the people you're working together, like when you start talking with them. If you don't, it's sometimes an awkward situation. (Participant 7, male, GPA $=3.17$, African)

I came in class and I was just looking at random strangers and like, 'I have to work with them for eight weeks?' And we were sitting there like 'oh my god' and we were all, like, having the same feeling. (Participant 16, male, GPA $=4.83$, German)

Participants in cluster 3 also all discussed the role of the teacher or tutor in creating a positive social atmosphere in the classroom. Unlike those in cluster 2, participants in cluster 3 were much more positive about the teacher's ability to decrease social tensions, even in small ways:

Well, our first tutor was awesome. He was there during the groups and talking to us, asking our plans for the weekend. Now ... we have absolutely no personal contact with them [my current tutors]. They never ask, 'how was your weekend?' That's just a small sentence but it makes you more comfortable. (Participant 10, female, GPA $=3.83$, Eastern European)

Six of the seven participants in this cluster also demonstrated more of a desire for the teacher to play an active role in developing the social atmosphere, by providing more activities such as icebreakers. 
What I've seen that helps a lot, like the first day that I got to [university name] we had this introduction day. What we started doing first, I think we played a few games. That helped people ease up. I think if the group work starts with a social activity first, that can definitely help make everybody feel at ease and more likely to interact better. (Participant 3, male, GPA = 4.50, African)

There was this one tutor, a German woman, really organized, and she made criteria for us [in our introductions] like, 'You have to say your name, you have to say your age, and you have to tell us the most embarrassing moment that happened to you in [university name]' ... But because of that, because of how she made us do these things, we really got along good. (Participant 8, male, GPA = 3.33, Eastern European)

The seventh participant (a domestic student), however, felt that teachers should instead focus on encouraging engagement through enthusiastic teaching.

I would definitely say that how they act influences and affects the students. If they are unhappy, the students will be unhappy. If they are enthusiastic, then it will rub off on the students and they will be enthusiastic. (Participant 11, female, GPA $=4.33$, Dutch)

In summary, participants in cluster 3 were much more likely to feel that social relationships are an essential component to group work. They were also more likely to highlight the prevalence of social tensions in group work and express a desire for more interventions and resources to create a more comfortable environment.

\section{Discussion}

Previous literature has highlighted that tensions exist in cross-cultural collaboration (Fozdar and Volet 2012; Harrison and Peacock 2009; Moore and Hampton 2015). In this article, we have added to the understanding of these tensions by considering the role of social relationships in cross-cultural group work. In terms of research question 1, we found that all students interviewed felt that social relationships are necessary components of cross-cultural collaboration. In every case, students wanted more opportunities to get to know their peers before working on group-related tasks, particularly when group members were from countries other than their own. Indeed, many participants in this study believed that cross-cultural group work tensions derive in part from a lack of social relationships between diverse group members. Thus, it is worth considering if the difficulties of cross-cultural group work highlighted in previous research (Kimmel and Volet 2012; Moore and Hampton 2015; Takahashi and Saito 2013) could be alleviated with increased opportunity for group members to form social relationships within and outside the classroom. Further research, thus, should consider which evidence-based interventions can support social relationships in collaborative work.

Participant perspectives on the role of social relationships did, however, have subtle variations, which can in part be explained by academic performance level (i.e. research question 2). High-performing students often demonstrated a desire for stronger relationships with group members to make assignments more 'fun', and to help 'other,' less confident students feel more comfortable. At the same time, mid- to low-performing students were much more likely to cite social tensions that disrupt the group work process. Lower performing students, in particular, felt that their academic experience could be improved by increased opportunities to build social relationships with peers. This gives deeper insight into previous 
quantitative research, which highlights that lower performing students are more likely to have fewer social learning connections with classmates in comparison to high-performing students (Gasevic et al. 2013; Hommes et al. 2012). Yet, this present study sheds only a partial light on why these views differ between those of varying academic performance levels, which gives cause for more needed research on this phenomenon. Understanding the root cause for poor social capital is important, after all, as Maunder et al. (2013) have previously highlighted social support as an essential factor for successful student transitions to university.

One possible explanation for the differences in these perceptions is that high-performing students are more likely to demonstrate social capital and diverse relationships, as demonstrated in previous research (Rienties et al. 2015). However, more research is needed to understand whether poor social capital is a symptom or a cause of low performance. One explanation could be that lower performing students enter university with fewer competencies needed to encourage social network building, as has been suggested in related research (see, for example: Parker et al. 2006). Yet, it is equally plausible that low academic performance leads students to withdraw from the classroom social space, as suggested previously (Wilcox et al. 2005). Thus, future research should unpack the factors (and their sequencing) that lead low-performing students to demonstrate less social integration than their higher performing peers.

Finally, research question 3 considered student perceptions of their teacher's role in decreasing social tensions. To this, participant views again varied widely by academic performance level. High-performing students demonstrated self-autonomy and often believed that forming social relationships between diverse students is an individual responsibility. They were also more likely to depict a 'utopian' vision of attitudes towards diversity at the university, often highlighting that social stratification and cultural clashes did not occur on campus and that harmony among students is 'natural.' However, mid- to low-performing students were much more likely to desire teacher intervention with activities such as in-depth introductions or icebreakers. Low-performing students, in particular, felt that improving social conditions within the classroom was the duty of their teachers. Thus, low-performing students were more likely to blame poor social conditions on the lack of teacher intervention. This adds depth to previous literature on the role of social integration and its influence on academic performance and progression (Gasevic et al. 2013; Hommes et al. 2012), a notion which has important implications for institutions and practitioners. Indeed, these findings suggest that resources for building social capital are needed and desired by certain student demographics on university campuses, as suggested in related research on student adjustment experiences (see Gareis 2012; Maunder et al. 2013). It is worth considering in future research, therefore, which evidence-based interventions by the classroom teacher can encourage low-performing students to feel more socially integrated with their peers.

\section{Limitations}

In this article, robust quantitative tools were used to select 20 students from a larger classroom of 860 students to participate in an in-depth interview about their experiences with social tensions in cross-cultural group work. In doing so, several limitations are recognised. First, this study took place in just one context and replication in other contexts will be necessary to confirm findings. Secondly, the focus of this study was on student reflections on cross-cultural group work, and, thus, did not include more objective measures of their experiences, such as by using social network analysis or observations of group work activities. Finally, we 
recognise that individual students should not be essentialised as collective identities from entire countries or regions. Indeed, more research will be needed in the future to further unpack variations in group work experiences between cultures. However, in contrast to previous quantitative and qualitative studies, we were able to select a representative, broad sample of students using cluster analysis techniques of academic performance. We also incorporated a unique mediating artefact method to elicit in-depth responses about personal topics, such as culture and social integration. This allowed us to provide a comprehensive, complex picture of how international and host national students overcome cross-cultural group work tensions.

\section{Conclusions}

This innovative study builds on previous research that highlights the potential role of social relationships in cross-cultural collaboration. In doing so, we have found that motivations for building social relationships with group members differ between students of various academic performance levels. Lower performing students, in particular, demonstrated a desire for teacher intervention to encourage relationship building in the classroom. Therefore, it is worth considering in the future which evidence-based interventions can drive social cohesion in the classroom and further encourage low-performing students to socially integrate with their higher performing peers. After all, a key takeaway from this present study is that social relationships are a desired component of the academic experience by all students, and thus an important consideration for the universities that serve them.

Open Access This article is distributed under the terms of the Creative Commons Attribution 4.0 International License (http://creativecommons.org/licenses/by/4.0/), which permits unrestricted use, distribution, and reproduction in any medium, provided you give appropriate credit to the original author(s) and the source, provide a link to the Creative Commons license, and indicate if changes were made.

\section{References}

Akyol, Z., \& Garrison, D. R. (2013). Educational communities of inquiry: theoretical framework, research and practice. Hershey, PA: IGI Global.

Bahn, S., \& Barratt-Pugh, L. (2013). Getting reticent young male participants to talk: using artefact-mediated interviews to promote discursive interaction. Qualitative Social Work, 12(2), 186-199.

Bliss, C. A., \& Lawrence, B. (2009). Is the whole greater than the sum of its parts? A comparison of small group and whole class discussions board activity in online courses. Journal of Asynchronous Learning Networks, 13(4), 25-39.

Chang, J.-S. (2006). A transcultural wisdom bank in the classroom: making cultural diversity a key resource in teaching and learning. Journal of Studies in International Education, 10(4), 369-377.

Curșeu, P. L., Janssen, S. E. A., \& Raab, J. (2011). Connecting the dots: social network structure, conflict, and group cognitive complexity. Higher Education, 63(5), 621-629.

Davies, W. M. (2009). Group work as a form of assessment: common problems and recommended solutions. The International Journal of Higher Education and Educational Planning, 58, 563-584.

Decuyper, S., Dochy, F., \& Van den Bossche, P. (2010). Grasping the dynamic complexity of team learning: an integrative model for effective team learning in organisations. Educational Research Review, 5(2), 111-133.

Denson, N., \& Zhang, S. (2010). The impact of student experiences with diversity on developing graduate attributes. Studies in Higher Education, 35(5), 529-543.

Fozdar, F., \& Volet, S. (2012). Intercultural learning among community development students: positive attitudes, ambivalent experiences. Community Development, 43(3), 361-378.

Gareis, E. (2012). Intercultural friendship: effects of home and host region. Journal of International and Intercultural Communication, 5(4), 309-328. 
Garrison, D. R., Anderson, T., \& Archer, W. (1999). Critical inquiry in a text-based environment: computer conferencing in higher education. The Internet and Higher Education, 2(2-3), 87-105.

Gasevic, D., Zouaq, A., \& Janzen, R. (2013). “Choose your classmates, your GPA is at stake!”: the association of cross-class social ties and academic performance. American Behavioral Scientist, 57, 1460-1479.

Gijselaers, W. H. (1995). Perspectives on problem-based learning. Dordrecht, Boston, London: Kluwer Academic Publishers.

Harrison, N., \& Peacock, N. (2009). Cultural distance, mindfulness and passive xenophobia: using integrated threat theory to explore home higher education students' perspectives on 'internationalisation at home'. British Educational Research Journal, 36(6), 2009.

Hommes, J., Rienties, B., de Grave, W., Bos, G., Schuwirth, L., \& Scherpbier, A. (2012). Visualising the invisible. A network approach to reveal the informal social side of student learning. Advances in Health Sciences Education, 17(5), 743-757.

Kember, D. (2008). Nurturing generic capabilities through a teaching and learning environment which provides practise in their use. Higher Education, 57(1), 37-55.

Kimmel, K., \& Volet, S. (2012). University students' perceptions of and attitudes towards culturally diverse group work: does context matter? Journal of Studies in International Education, 16(2), 157-181.

Lavy, S. (2016). Who benefits from group work in higher education? An attachment theory perspective. Higher Education, 1-13.

Levin, P. (2005). Successful teamwork. New York: McGraw-Hill Education.

Lichtman, M. (2013). Qualitative research in education: a user's guide (3rd ed.). Thousand Oaks, California: Sage.

Mathieu, J. E., Heffner, T. S., Goodwin, G. F., Salas, E., \& Cannon-Bowers, J. A. (2000). The influence of shared mental models on team processes and performance. Journal of Applied Psychology, 85(2), 273-282.

Maunder, R. E., Cunliffe, M., Galvin, J., Mjali, S., \& Rogers, J. (2013). Listening to student voices: student researchers exploring undergraduate experiences of university transition. Higher Education, 66(2), 139-152.

Mittelmeier, J., Héliot, Y., Rienties, B., \& Whitelock, D. (2016). Using Social Network Analysis to predict online contributions: The impact of network diversity in cross-cultural collaboration. Paper presented at the Web Science 2016 conference, Hannover, Germany.

Moore, P., \& Hampton, G. (2015). 'It's a bit of a generalisation, but...': participant perspectives on intercultural group assessment in higher education. Assessment \& Evaluation in Higher Education, 40(3), 390-406.

OECD. (2014). Education at a glance 2014: OECD indicators. from http://www.oecd.org/edu/Education-at-aGlance-2014.pdf

Parker, J. D. A., Hogan, M. J., Eastabrook, J. M., Oke, A., \& Wood, L. M. (2006). Emotional intelligence and student retention: predicting the successful transition from high school to university. Personality and Individual Differences, 41(7), 1329-1336.

Rienties, B., Johan, N., \& Jindal-Snape, D. (2015). Bridge building potential in cross-cultural learning: A mixed method study. Asia Pacific Education Review, 16(1), 37-48.

Rienties, B., Alcott, P., \& Jindal-Snape, D. (2014). To let students self-select or not: that is the question for teachers of culturally diverse groups. Journal of Studies in International Education, 18(1), 64-83.

Rienties, B., Heliot, Y., \& Jindal-Snape, D. (2013). Understanding social learning relations of international students in a large classroom using social network analysis. Higher Education, 66, 489-504.

Rienties, B., Hernandez Nanclares, N., Jindal-Snape, D., \& Alcott, P. (2013). The role of cultural background and team divisions in developing social learning relations in the classroom. Journal of Studies in International Education, 17(3), 332-353.

Schartner, A. (2015). 'You cannot talk with all of the strangers in a pub': a longitudinal case study of international postgraduates students' social ties at a British university. Higher Education, 69(2), 225-241.

Sherry, M., Thomas, P., \& Chui, W. H. (2010). International students: a vulnerable student population. Higher Education, 60(1), 33-46.

Singaram, V. S., van der Vleuten, C. P. M., Stevens, F., \& Dolmans, D. H. J. M. (2011). "For most of us Africans, we don't just speak": a qualitative investigation into collaborative heterogeneous PBL group learning. Advances in Health Sciences Education, 16(3), 297-310.

Spencer-Oatey, H., \& Dauber, D. (2017). The gains and pains of mixed national group work at university. Journal of Multilingual and Multicultural Development.

Takahashi, S., \& Saito, E. (2013). Unraveling the process and meaning of problem-based learning experiences. Higher Education, 66(6), 693-706.

Van den Bossche, P., Gijselaers, W. H., Segers, M., \& Kirschner, P. A. (2006). Social and cognitive factors driving teamwork in collaborative learning environments: team learning beliefs and behaviour. Small Group Research, 37(490-521).

Wang, Y. (2012). Mainland Chinese students' group work adaptation in a UK business school. Teaching in Higher Education, 17(5), 523-535. 
Wilcox, P., Winn, S., \& Fyvie-Gauld, M. (2005). It was nothing to do with the university, it was just the people: the role of social support in the first-year experience of higher education. Studies in Higher Education, 30(6), $707-722$.

Zaitseva, E., Milsom, C., \& Stewart, M. (2013). Connecting the dots: using concept maps for interpreting student satisfaction. Quality in Higher Education, 19(2), 225-247. 